\title{
Rapid Tumor Necrosis Factor $\alpha$-Induced Exocytosis of Glutamate Receptor 2-Lacking AMPA Receptors to Extrasynaptic Plasma Membrane Potentiates Excitotoxicity
}

\author{
Dmitri Leonoudakis, Pingwei Zhao, and Eric C. Beattie \\ California Pacific Medical Center Research Institute, San Francisco, California 94107
}

\begin{abstract}
The postinjury inflammatory response in the CNS leads to neuronal excitotoxicity. Our previous studies show that a major component of this response, the inflammatory cytokine tumor necrosis factor $\alpha$ (TNF $\alpha)$, causes a rapid increase in AMPA glutamate receptors (AMPARs) on the plasma membrane of cultured hippocampal neurons. This may potentiate neuron death through an increased vulnerability to AMPAR-dependent excitotoxic stress. Here, we test this hypothesis with an in vitro lactose dehydrogenase death assay and examine in detail the AMPAR surface delivery time course, receptor subtype, and synaptic and extrasynaptic distribution after TNF $\alpha$ exposure. These data demonstrate that surface levels of glutamate receptor 2 (GluR2)-lacking $\mathrm{Ca}^{2+}$-permeable AMPARs peak at $15 \mathrm{~min}$ after TNF $\alpha$ treatment, and the majority are directed to extrasynaptic sites. TNF $\alpha$ also induces an increase in GluR2-containing surface AMPARs but with a slower time course. We propose that this activity contributes to excitotoxic neuron death because TNF $\alpha$ potentiation of kainate excitotoxicity is blocked by a $\mathrm{Ca}^{2+}$-permeable AMPAR antagonist [NASPM (1-naphthyl acetyl spermine)] and a specific phosphoinositide 3 kinase (PI3 kinase) inhibitor (LY294,002 [2-(4-morpholinyl)-8-phenyl-4H-1-benzopyran-4-one]) previously shown to block the TNF $\alpha$-induced increase in AMPAR surface delivery. This information forms the basis for future in vivo studies examining AMPAR-dependent potentiation of excitotoxic neuron death and dysfunction caused by TNF $\alpha$ after acute injury and during neurodegenerative or neuropsychiatric disorders.
\end{abstract}

Key words: TNF $\alpha$; AMPAR; trafficking; extrasynaptic; excitotoxicity; calcium-permeable

\section{Introduction}

Neurodegenerative disease and postinjury environments are characterized by abnormally high levels of the cytokine tumor necrosis factor $\alpha(\mathrm{TNF} \alpha)$, a major component of the inflammatory process responsible for neuronal cytotoxicity and dysfunction (Shohami et al., 1999; Perry et al., 2001; Szelenyi, 2001). The specific mechanisms of TNF $\alpha$-induced neuronal cytotoxicity are unclear. Several studies have searched for the roots of this cytotoxicity by focusing on the protein translation-dependent apoptotic signaling pathways that are part of the complex signaling cascades elicited by TNF $\alpha$ (Zhao et al., 2001; Fontaine et al., 2002; Yang et al., 2002; Zou and Crews, 2005). Recent studies suggest an alternate mechanism for the induction of TNF $\alpha$-induced neuron death through the rapid TNF $\alpha$-induced surface expression of AMPA-type glutamate receptors (AMPARs) (Beattie et al., 2002; Ogoshi et al., 2005; Stellwagen et al., 2005). The precise regulation of AMPAR numbers on the postsynaptic plasma membrane is

Received July 26, 2007; revised Dec. 17, 2007; accepted Dec. 18, 2007.

This work was supported by National Institutes of Health Grants MH067931 and NS038079 as well as by The Forbes Norris ALS Center, the California Pacific Medical Center Research Institute, and ALS Association Starter Grant 766. We thank Ruth Chu and Jae-Young Seo for expert technical assistance with hippocampal dissection. We thank Steven Braithwaite, Dave Stellwagen, Michael Beattie, Jacqueline Bresnahan, Adam Ferguson, and Brandon Miller for critical discussions and suggestions.

Correspondence should be addressed to Eric C. Beattie, California Pacific Medical Center Research Institute, 475 Brannan Street, Suite 220, San Francisco, CA 94107. E-mail: beattie@cpmcri.org.

DOI:10.1523/JNEUROSCI.5159-07.2008

Copyright $\odot 2008$ Society for Neuroscience $\quad$ 0270-6474/08/282119-12\$15.00/0 essential for the control of synaptic efficacy (Carroll et al., 2001; Malinow and Malenka, 2002; Song and Huganir, 2002; Bredt and Nicoll, 2003), but disregulation of their trafficking may contribute to excitotoxic vulnerability (Leonoudakis et al., 2004; Pickering et al., 2005).

Our previous work shows that TNF $\alpha$ rapidly increases steadystate glutamate receptor 1 (GluR1)-containing AMPAR total cell surface accumulation $15 \mathrm{~min}$ after application to hippocampal neuron cultures (Beattie et al., 2002) through a phosphoinositide 3 kinase (PI3K)-dependent mechanism (Stellwagen et al., 2005). This activity can be observed in cortical neurons (Leonoudakis et al., 2004) as well as in intact spinal cord (Fergusen et al., 2006), suggesting that this is a general response of neurons to TNF $\alpha$ and postinjury inflammation across the CNS. Increased TNF $\alpha$ levels in the CNS contribute to AMPAR-dependent neuron death (Hermann et al., 2001; Noh et al., 2005), and specific blockade of $\mathrm{Ca}^{2+}$-permeable AMPARs (CP-AMPARs) prevents excitotoxicity in intact spinal cord (Corona and Tapia, 2007). These data are consistent with the hypothesis that TNF $\alpha$ induces a rapid rise in CP-AMPARs, which contribute to excitotoxic vulnerability.

Here, we detail the TNF $\alpha$-induced increase in surface AMPAR levels, concentrating on the spatiotemporal trafficking and subunit composition in cultured hippocampal neurons as well as the functional relevance to excitotoxic vulnerability. We used live fluorescence microscopy of hippocampal neurons to demonstrate that the TNF $\alpha$-induced increase in surface AMPAR accu- 
mulation is attributable to increased exocytosis of internally derived receptors to the neuron plasma membrane. We used biochemical and immunofluorescent microscopy techniques to describe the $1 \mathrm{~h}$ time course and synaptic/extrasynaptic distribution of AMPAR surface delivery after TNF $\alpha$ exposure. These data are supportive of GluR2-lacking CP-AMPAR exocytosis to extrasynaptic plasma membrane within 15 min of exogenous TNF $\alpha$ application followed by an increase in GluR2-containing AMPARs after $1 \mathrm{~h}$. Using an in vitro neuron death assay with pharmacological control of AMPAR trafficking and activity, we demonstrated that CP-AMPAR activity is required for $\mathrm{TNF} \alpha$ potentiation of neuron death. Compounds that block TNF $\alpha$ induced AMPAR exocytosis to the plasma membrane block this neuron death. These data reveal a role for TNF $\alpha$ in initiating neuron death by trafficking CP-AMPARs to the extrasynaptic plasma membrane after the neuroinflammation process.

\section{Materials and Methods}

Hippocampal cultures. The primary hippocampal neuron culture protocol is modified from that of Banker and Goslin (1998) and described in detail by Beattie et al. (2002). Briefly, hippocampi of embryonic day 18 (E18) Sprague Dawley rats were removed, digested with papain, and dissociated by trituration. Neurons were plated in Neurobasal medium containing B27 supplement and Glutamax (Invitrogen, Carlsbad, CA) on coverslips or plastic plates coated with poly-D-lysine. After cell attachment $(3-4 \mathrm{~h})$, the medium was replaced. Three days later, an equal volume of Neurobasal medium containing N2 supplement and Glutamax was added. Cultures were fed weekly by replacing one-half of the medium with Neurobasal/N2/Glutamax. Astrocyte growth was inhibited by adding 5 -fluoro- 2 '-deoxyuridine on $6 \mathrm{~d}$ in vitro (div). Cultures were used for experiments between weeks 3 and 4 .

Immunofluorescence AMPAR surface localization. Before neuron treatment, the medium was changed to prewarmed artificial CSF (ACSF) $(25$ mM HEPES, pH 7.4, $125 \mathrm{~mm} \mathrm{NaCl}, 2.5 \mathrm{~mm} \mathrm{KCl,} 1 \mathrm{~mm} \mathrm{MgCl}_{2}, 2 \mathrm{~mm}$ $\mathrm{CaCl}_{2}, 33 \mathrm{mM}$ D-glucose with the following receptor antagonists: $0.5 \mu \mathrm{M}$ tetrodotoxin, $3 \mu \mathrm{M}$ strychnine, $20 \mu \mathrm{M}$ bicuculline methiodide, and $20 \mu \mathrm{M}$ D-APV to eliminate the contributions of spontaneous action potentials, inhibitory signaling, and NMDA receptor activation, respectively) for $30 \mathrm{~min}$. The AMPAR antagonist CNQX had no effect on AMPAR surface expression, and the results presented represent experiments with and without this antagonist. Recombinant rat TNF $\alpha(100$ $\mathrm{ng} / \mathrm{ml}$; R\&D Systems, Minneapolis, MN) diluted in ACSF or ACSF alone (control) was added to neurons for the time indicated. After the indicated times, neurons were fixed with $4 \%$ paraformaldehyde $/ 4 \%$ sucrose in PBS for 10 min, washed with PBS, blocked with $3 \%$ BSA, $2 \%$ goat serum in PBS (blocking buffer) for $1 \mathrm{~h}$, and incubated with rabbit anti-GluR1 (Calbiochem, La Jolla, CA) antibodies and/or mouse anti-GluR2 antibodies (BD Biosciences, San Jose, CA) (both against extracellular epitopes) overnight at $4^{\circ} \mathrm{C}$. Cells were washed three times with PBS and incubated for $45 \mathrm{~min}$ at room temperature with goat anti-rabbit Alexa Fluor 555 and/or goat anti-mouse Alexa Fluor 488 (Invitrogen) diluted in blocking buffer. Cells were washed and coverslips were mounted on slides with Fluoromount G (Electron Microscopy Sciences, Hatfield, PA). Fluorescence microscopy was performed on a TE2000 Nikon (Tokyo, Japan) inverted microscope with a Photometrics (Tucson, AZ) Coolsnap HQ CCD camera controlled by MetaMorph software (Molecular Devices, Downingtown, PA). For individual experiments, images for all conditions were analyzed using identical acquisition parameters as described previously (Beattie et al., 2002; Stellwagen et al., 2005). For dendritic analysis, regions of equal size containing dendrites at least $5 \mu \mathrm{m}$ away from the soma were selected and used for quantitation as above. For postsynaptic density-95 (PSD-95) colocalization, cell surface labeling was performed as above. Cells were then permeabilized with $0.2 \%$ Triton $\mathrm{X}-100$ and incubated with a mouse monoclonal anti-PSD-95 antibody (Affinity BioReagents, Golden, CO) for $1 \mathrm{~h}$. Colocalization of PSD-95 and AMPAR subunits was examined by imaging neurons with a single 0.5 - $\mu$ m-thick plane at $1024 \times 1024$ pixel resolution with a Nikon $\mathrm{C} 1$ confocal microscope. Colocalization of PSD-95 and AMPAR subunits was quantified by carefully tracing dendrites using the region measurement tool followed by the use of the "colocalization" feature of MetaMorph software.

AMPAR cell surface biotinylation and detection. To determine the amount of AMPAR subunit cell surface localization, we used a slight modification of an established protocol (Tsao and von Zastrow, 2000). High-density hippocampal neurons are plated on poly-D-lysine-coated six-well plates $(350,000$ cells $)$ or $10 \mathrm{~cm}$ dishes $\left(2 \times 10^{6}\right.$ cells $)$ and cultured for 3-4 weeks. The medium was changed to prewarmed ACSF with inhibitors as above. TNF $\alpha(100 \mathrm{ng} / \mathrm{ml})$ diluted in ACSF or no treatment (control) was added to neurons for the indicated times and incubated at $37^{\circ} \mathrm{C}$. Cells were then chilled on ice and washed with cold PBS containing $0.5 \mathrm{mM} \mathrm{Ca}^{2+}$ and $1 \mathrm{mM} \mathrm{Mg}^{2+}$ (PBSCM). Cell surface proteins were biotinylated with the membrane-impermeable reagent $\mathrm{NHS}-\mathrm{PEO}_{4}-$ biotin [15-([biotinoyl]amino)-4,7,10,13-tetraoxapentadecanoic acid, $\mathrm{N}$-hydroxysuccinimidylester] (Pierce, Rockford, IL) at a concentration of $0.25 \mathrm{mg} / \mathrm{ml}$ freshly diluted in PBSCM and incubated on ice for $20 \mathrm{~min}$. The reaction was quenched by two $10 \mathrm{~min}$ washes with chilled $100 \mathrm{~mm}$ glycine in PBSCM. Cells were scraped into $100 \mu \mathrm{l}$ per well (six-well plates) or $1 \mathrm{ml}$ per $10 \mathrm{~cm}$ plate RIPA lysis buffer (1\% NP-40, $0.5 \%$ deoxycholate, $0.1 \%$ SDS, $150 \mathrm{~mm} \mathrm{NaCl}$, Tris, $\mathrm{pH} 8.0$, with a protease inhibitor mixture; Roche, Palo Alto, CA), 1 mm EDTA, 1 mm EGTA, 1 mM PMSF, and the phosphatase inhibitors $50 \mathrm{~mm} \mathrm{NaF}, 100 \mathrm{~mm} \mathrm{Na}_{4} \mathrm{P}_{2} \mathrm{O}_{7}$, $10 \mathrm{~mm} \mathrm{Na} \beta$-glycerophosphate, $1 \mathrm{mM} \mathrm{Na}_{3} \mathrm{VO}_{4}$, solubilized for $1 \mathrm{~h}$ at $4^{\circ} \mathrm{C}$ on a rotator, and centrifuged for $15 \mathrm{~min}$ at $16,000 \times g$. Supernatant was removed and the protein concentration determined by the Bio-Rad (Hercules, CA) DC protein quantification assay.

Biochemical purification of surface AMPARs with streptavidin-agarose. An equal amount of protein $(100 \mu \mathrm{g})$ from each experimental condition was precipitated with streptavidin-agarose beads (Pierce) overnight at $4^{\circ} \mathrm{C}$ with rotation. Beads were washed three times with RIPA buffer, centrifuged through $1 \mathrm{~m}$ sucrose/RIPA, and washed once more, and proteins were eluted in SDS sample buffer. Eluted proteins were resolved by SDS-PAGE, transferred to polyvinylidene difluoride (PVDF), and immunoblotted with polyclonal anti-GluR1, polyclonal anti-NR1 (Chemicon, Temecula, CA), monoclonal anti-GluR2 (BD Biosciences), polyclonal anti-actin (Sigma-Aldrich, St. Louis, MO), and anti-PSD95 antibodies (Affinity BioReagents). To detect primary antibodies, blots were incubated goat anti-rabbit or goat anti-mouse antibodies conjugated to horseradish peroxidase (Jackson ImmunoResearch, West Grove, PA), visualized by enhanced chemiluminescence (Super Signal West Femto; Pierce) and digitally imaged with an Alpha Innotech (San Leandro, CA) imager. Before image processing, bands were quantified using Alpha Ease EC analysis software (Alpha Innotech). Figures are inverted images processed with Adobe Photoshop. Surface protein data were normalized to total actin in the lysate of each sample and were expressed as the percentage of untreated controls. Cell membrane integrity during the biotinylation reaction was assessed by immunoblotting the streptavidin-agarose purified protein samples for actin to insure that intracellular proteins were not labeled (data not shown).

For enrichment of synaptic and extrasynaptic surface AMPARs, neurons were biotinylated as above and proteins were solubilized in RIPA buffer containing only $1 \% \mathrm{NP}-40$ as the detergent, which does not solubilize postsynaptic densities (Chen et al., 2000; Oh et al., 2006). After incubation for $1 \mathrm{~h}$ at $4^{\circ} \mathrm{C}$, the homogenate was centrifuged at $100,000 \times$ $g$ for 30 min to pellet the insoluble material. The supernatant (enriched for extrasynaptic AMPARs) was removed, and the insoluble material (enriched for synaptic AMPARs) was solubilized with 1\% SDS and diluted 10 -fold with $1 \%$ NP-40 buffer. These two fractions were then subjected to the streptavidin-agarose pulldowns as above.

Immunoprecipitation and purification of GluR2-lacking GluR1. Detection of intracellular proteins was accomplished by immunoprecipitation of the supernatants of biotinylated extracts previously cleared of surface protein by streptavidin-agarose precipitation described above. A total of $1 \mu \mathrm{g}$ of rabbit anti-GluR1 (Chemicon) bound to protein A-agarose (Pierce) beads or $4 \mu \mathrm{g}$ of goat anti-GluR2 (Santa Cruz Biotechnology, Santa Cruz, CA) bound to protein G-agarose beads (Pierce) were incubated with extract for $2 \mathrm{~h}$ and washed as above. Immunoblot detection of 
precipitated proteins was performed with mouse monoclonal antiGluR1 (Santa Cruz Biotechnology) and mouse monoclonal anti-GluR2 (BD Biosciences).

For detection of surface-biotinylated GluR2-lacking, GluR1containing AMPARs, extract was prepared as above. To remove AMPAR complexes containing GluR2 (heteromeric GluR1/GluR2 or GluR2/3 AMPARs) (Oh and Derkach, 2005), equal amounts of protein (100 $\mu \mathrm{g})$ from each experimental condition were first precipitated with $2 \mu \mathrm{g}$ per immunoprecipitate (IP) goat anti-GluR2 (Santa Cruz Biotechnology) prebound to protein $\mathrm{G}$-agarose (Pierce) overnight at $4^{\circ} \mathrm{C}$. Immunoprecipitates were obtained by centrifugation and the supernatant was immunoprecipitated a second time with fresh $2 \mu \mathrm{g}$ per IP anti-GluR2/ protein G-agarose for $2 \mathrm{~h}$ at $4^{\circ} \mathrm{C}$ to ensure the removal of GluR2containing AMPARs from the supernatant. The immunoprecipitate was collected by centrifugation and combined with the first immunoprecipitation. The supernatant, cleared of all detectable GluR2-containing AMPARs, was subjected to steptavidin-agarose immunoprecipitation as above followed by immunoblot detection with rabbit anti-GluR1 (Chemicon) detection as above.

Live imaging of superecliptic pHluorin-tagged GluR1 in hippocampal neurons. A cDNA encoding superecliptic pHluorin (SEP) preceded by a cleavable signal sequence was PCR-amplified using an SEP-tagged adrenergic receptor as template (Yudowski et al., 2006) and fused in-frame between codons 3 and 4 of the cDNA encoding rat GluR1 (Boulter et al., 1990) (flop; accession no. P19490; provided by S. Heinemann, Salk Institute, San Diego, CA), using 5'-EcoR1 and $3^{\prime}$-BssHI restriction sites, and inserted into the CMV (cytomegalovirus)-based mammalian expression vector $\mathrm{pRK5}$.

Rat hippocampal neurons were either transfected by AMAXA nucleofection (AMAXA, Gaithersburg, MD) before plating or with Lipofectamine 2000 (Invitrogen) on div 7 with the SEP-GluR1 construct. The 14-17 div neurons were imaged live at $37^{\circ} \mathrm{C}$ by scanning confocal microscopy (Nikon C1 laser-scanning confocal attached to a Nikon TE2000 microscope) in ACSF with 500 nм TTX, $20 \mu \mathrm{m}$ bicuculline methiodide, 3 $\mu \mathrm{M}$ strychnine, and $20 \mu \mathrm{M}$ D-AP5. Neurons were imaged before bleaching, and then surface SEP-GluR1-containing AMPARs were bleached with maximum illumination from the mercury bulb light source for 1 min and allowed to recover in the presence or absence of $100 \mathrm{ng} / \mathrm{ml}$ TNF $\alpha$. This protocol reduces the surface background caused by AMPARs already at the surface and allows for the efficient detection of newly delivered AMPARs derived from internal sources (Yudowski et al., 2007). Internal SEP-GluR1 containing AMPARs are not bleached by this technique because they are not at the appropriate $\mathrm{pH}$ and therefore not fluorescent. Images shown are maximum projections of $11 z$-series images taken at $0.5 \mu \mathrm{m}$ intervals. Images were then analyzed for changes in fluorescence intensity by setting a low threshold for images immediately after bleaching and comparing to $15 \mathrm{~min}$ of recovery with and without TNF $\alpha$ using the same low threshold with MetaMorph software.

Lactose dehydrogenase excitotoxicity assay. Lactose dehydrogenase $(\mathrm{LDH})$ is a stable cytosolic enzyme released during cell lysis from dead or dying cells and was used as a quantitative measure of neuron toxicity and death (Patel et al., 1993; Glass et al., 2004). Hippocampal neurons were plated at a density of 75,000 cells per well of a 24 -well plate and used for assay on div 16-17. Neurons were left untreated (control) or pretreated with $100 \mathrm{ng} / \mathrm{ml} \mathrm{TNF} \alpha, 10 \mu \mathrm{M}$ CNQX (nonselective AMPAR antagonist), $50 \mu \mathrm{M}$ 1-naphthyl acetyl spermine (NASPM) (synthetic joro spider toxin analog; $\mathrm{Ca}^{2+}$-permeable AMPAR antagonist), $50 \quad \mu \mathrm{M}$ 2-(4morpholinyl)-8-phenyl-4H-1-benzopyran-4-one [LY294,002 (LY)] (PI3K inhibitor), or drug plus TNF $\alpha$ for $15 \mathrm{~min}$. Kainate (KA) at $20 \mu \mathrm{M}$ was then added to the appropriate conditions in a final volume of $250 \mu \mathrm{l}$ for $18 \mathrm{~h}$ at $37^{\circ} \mathrm{C}$. Each condition was replicated in quadruplicate for each independent experiment. The medium was removed, centrifuged to remove particulate matter, and the supernatant of each sample was assayed in triplicate for colorimetric measurement of $\mathrm{LDH}$ activity using the LDH CytoTox 96 Assay kit following the manufacturer's instructions (Promega, Madison, WI). Each experiment was normalized to control, untreated conditions, and the data from four experiments were compiled.

Statistics. Populations are described as mean \pm SEM and statistical significance was determined by the Student's paired $t$ test (two populations) or $z$ test (immunoblots; two populations). Each experiment was repeated at least three times, and the $n$ values represent the number of individual neurons for immunofluorescence microscopy and number of experiments for immunoblotting.

\section{Results \\ The surface delivery of GluR1 and GluR2-containing AMPARs over $1 \mathrm{~h}$ of TNF $\alpha$ exposure}

Our previous immunofluorescence microscopy studies examining the effect of TNF $\alpha$ on GluR1 surface localization in hippocampal neurons used a single time point of 15 min to show that TNF $\alpha$ dramatically increases AMPAR surface delivery (Beattie et al., 2002; Stellwagen et al., 2005). Our present studies use in vitro TNF $\alpha$ treatment of hippocampal neurons to detail the trafficking of AMPARs specifically induced by this singular component of the inflammatory response that neurons experience in vivo after injury. After neurotrauma, $\mathrm{TNF} \alpha$ concentrations around CNS neurons rise rapidly above normal levels and these concentrations are maintained for hours to days after the injury (Allan and Rothwell, 2001). We used $100 \mathrm{ng} / \mathrm{ml} \mathrm{TNF} \alpha$ (used in all of the following experiments) because (1) this concentration is physiologically relevant as shown by studies of TNF $\alpha$ concentration in vivo in the circulation of rats after LPS exposure (Nemeth et al., 1997), and (2) this was the maximum effective concentration for the induction of AMPAR surface localization in our previous in vitro dose-response studies (Beattie et al., 2002). After CNS injury, there is also excessive glutamate release from presynaptic neurons and from astrocytes, which bathes the extrasynaptic as well as synaptic plasma membrane of the postsynaptic neuron (Allan and Rothwell, 2001). Thus, if surface AMPARs (and in particular CP-AMPARs) are maintained above normal levels on the plasma membrane (synaptic, extrasynaptic, or both), the vulnerability of neurons to excitotoxicity should also be increased. To measure the longevity of the TNF $\alpha$-induced surface localization of AMPARs and to examine the subunit composition of these receptors that arrive at the plasma membrane, we used quantitative immunofluorescence to detect total surface GluR1 (synaptic plus extrasynaptic) or GluR2-containing AMPARs over a $1 \mathrm{~h}$ time course of TNF $\alpha$ exposure. Neurons were treated with TNF $\alpha$ for 15, 30, or 60 min or left untreated (control) as described in Materials and Methods. To detect only surface receptors, neurons were fixed without permeabilization and processed for indirect immunofluorescence visualization using extracellular epitope-directed anti-GluR1 and anti-GluR2 antibodies and imaged with wide-field fluorescence microscopy (Fig. 1A,B). We observed a $\sim 50 \%$ increase over control in GluR1 surface localization after just $15 \mathrm{~min}$ of TNF $\alpha$ treatment ( $148 \pm 12 \%$ of untreated cultures; $n=87 ; p<0.01$ ) (Fig. $1 A, C$ ). Incubation with $\mathrm{TNF} \alpha$ for 30 min maintained a significant increase in GluR1 surface localization but to a lesser extent than at the 15 min time point $(131 \pm 11 \% ; n=87 ; p<0.05)$ (Fig. $1 C)$. By 60 min of TNF $\alpha$ treatment, the levels of surface GluR1 had returned to near control levels $(109 \pm 10 \% ; n=51)$ (Fig. 1 A,C). Thus, this application of continuously available TNF $\alpha$ caused a rapid and significant increase in surface GluR1 that reached a peak at 15 min of treatment and returned to near baseline levels at $60 \mathrm{~min}$ (Fig. $1 A, C)$.

Our analysis of the surface localization of GluR2 over this time course did not detect a significant increase (15 min, $111 \pm 15 \%$, $n=56 ; 30 \mathrm{~min}, 110 \pm 16 \%, n=57 ; 60 \mathrm{~min}, 129 \pm 15 \%, n=52)$; however, there was a trend of the data toward increased surface GluR2 reaching a maximum at $60 \mathrm{~min}$ (Fig. $1 B, C$ ) that was con- 


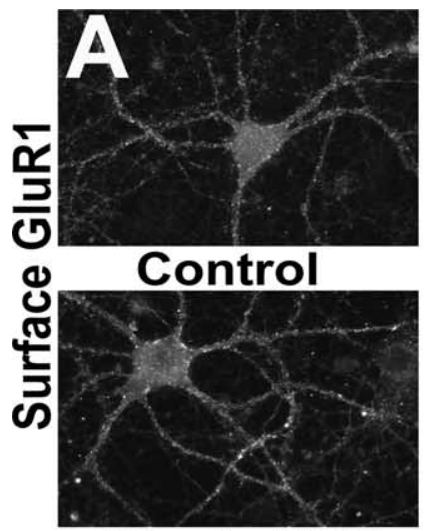

$30 \mathrm{~min}$ TNF

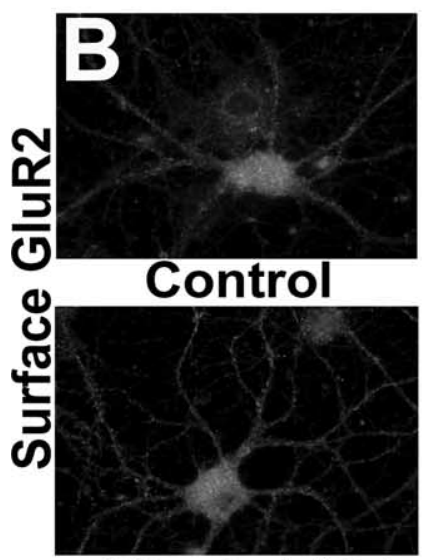

$30 \mathrm{~min}$ TNF

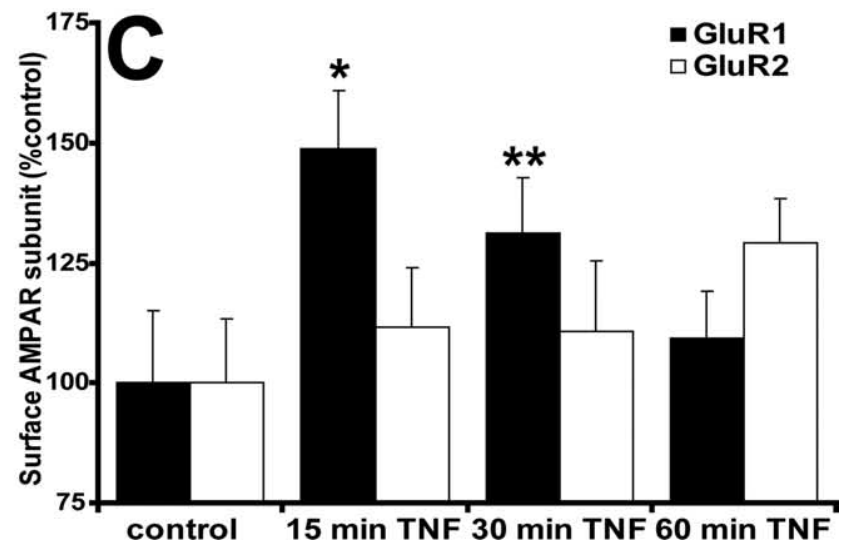

Figure 1. TNF $\alpha$ induces rapid and transient delivery of endogenous GluR1 to the plasma membrane as shown by quantitative immunofluorescence microscopy. $\boldsymbol{A}, \boldsymbol{B}$, The 17-21 div hippocampal neurons were either treated with TNF $\alpha$ for 15, 30, 60 min or left untreated (control). Neurons were fixed without membrane permeabilization and processed for indirect immunofluorescence using extracellular epitope-directed anti-GluR1 (A) and anti-GluR2 (B) antibodies. Images were acquired using wide-field fluorescence microscopy and were thresholded and quantified using MetaMorph software (see Materials and Methods). Compiled data for GluR1 and GluR2 is expressed in bar graph (C). Error bars indicate SEM. ${ }^{*} p<0.01$; ${ }^{* *} p<0.05$; $n=56-87$ cells from eight different experiments.

firmed by significant changes seen in the biochemistry below. Future studies using longer time course exposure to TNF $\alpha$ will test our hypothesis that GluR2-containing receptors gradually replace the GluR2-lacking AMPARs that show this dramatic but transient increase in surface localization.
Quantitation of surface and internal pools of GluR1- and GluR2-containing AMPARs over $1 \mathrm{~h}$ of TNF $\alpha$ exposure

We used the above immunofluorescence microscopy assays with success to examine increases in discrete aggregations of surface AMPARs or puncta above a given intensity threshold. Much of this analysis then is weighted toward the detection of punctate surface AMPARs, which are likely the aggregation of many individual receptors. We previously showed these AMPARcontaining puncta to be colocalized with both synaptic and extrasynaptic plasma membrane (Beattie et al., 2002). Therefore, to ensure the detection of all surface receptors, even singular AMPARs that might be below the threshold level of our microscopic analysis, we used cell surface biotinylation followed by Western blot analysis to track AMPAR surface localization over a $1 \mathrm{~h}$ time course of TNF $\alpha$ exposure. Hippocampal neurons were treated with TNF $\alpha$ for 15, 30, or $60 \mathrm{~min}$, and surface biotinylated (see Materials and Methods). Cells were lysed and the surface biotinylated proteins were purified by streptavidin-agarose precipitation. After SDS-PAGE and electrophoretic membrane transfer, the membrane was probed with either anti-GluR1 or anti-GluR2 antibodies. Initial control experiments demonstrated an increase in surface GluR1 after $15 \min \mathrm{TNF} \alpha$ (Fig. $2 A$ ) as seen in the immunofluorescence experiments above (Fig. 2B) $(127 \pm 7 \%$ compared with control; $n=7)$. As a positive control for increased AMPAR surface expression, we used a long-term potentiation chemical induction protocol (chemLTP treatment, $200 \mu \mathrm{M}$ glycine in ACSF buffer lacking $\mathrm{MgCl}_{2}$ and D-APV) (Lu et al., 2001; Oh and Derkach, 2005). ChemLTP treatment produced a similar increase in total surface GluR1 (Fig. 2 B) (128 $\pm 11 \%$ compared with control; $n=7$ ). To ensure that equal concentrations of hippocampal neuron protein extract were used for pulldown experiments, extract before the pulldown was immunoblotted for actin protein levels (Fig. $2 \mathrm{~A}$ ). To ensure that internal proteins were not being labeled during the surface biotinylation procedure, streptavidin-agarose precipitates were routinely immunoblotted for the intracellular protein actin. These controls did not detect actin, suggesting that the plasma membrane was not compromised during surface biotinylation (data not shown).

Using this cell surface biotinylation method, we analyzed both the total surface and total intracellular GluR1 and GluR2 AMPARs over a $1 \mathrm{~h}$ time course of TNF $\alpha$ treatment (Fig. 2 B). Our goal was to confirm our surface immunofluorescence observations and determine possible changes in intracellular and total protein levels of GluR1 and GluR2. The biotinylation/ streptavidin-agarose precipitation method described above was used to selectively purify surface AMPAR subunits from lysates of hippocampal cultures with an initial streptavidin pulldown. The GluR1 or GluR2 AMPAR subunits remaining in the supernatant were then immunoprecipitated using antibodies specific to GluR1 or GluR2. This final precipitation yields AMPAR subunits that were intracellularly localized at the time of surface biotinylation.

The surface biotinylation data agreed with the surface immunofluorescence data in that we observed an increase in surface GluR1 at $15 \mathrm{~min}$ of TNF $\alpha$ treatment $(134 \pm 11 \%$ of untreated cultures; $n=4 ; p<0.005$ ) (Fig. $2 C, D$ ). We noted that the significant increase in GluR1 surface expression was reduced to a nonsignificant level over control by $30 \mathrm{~min}$ of $\mathrm{TNF} \alpha$ treatment $(103 \pm 14 \% ; n=3)$ and remained at near control levels (nonsignificant) even after $60 \mathrm{~min}$ of TNF $\alpha$ treatment $(109 \pm 17 \%$; $n=$ 3 ), as seen in our microscopy. Biochemical analysis of surface GluR2 accumulation over $60 \mathrm{~min}$ of $\mathrm{TNF} \alpha$ treatment showed a steady increase to a significant level over untreated controls (15 

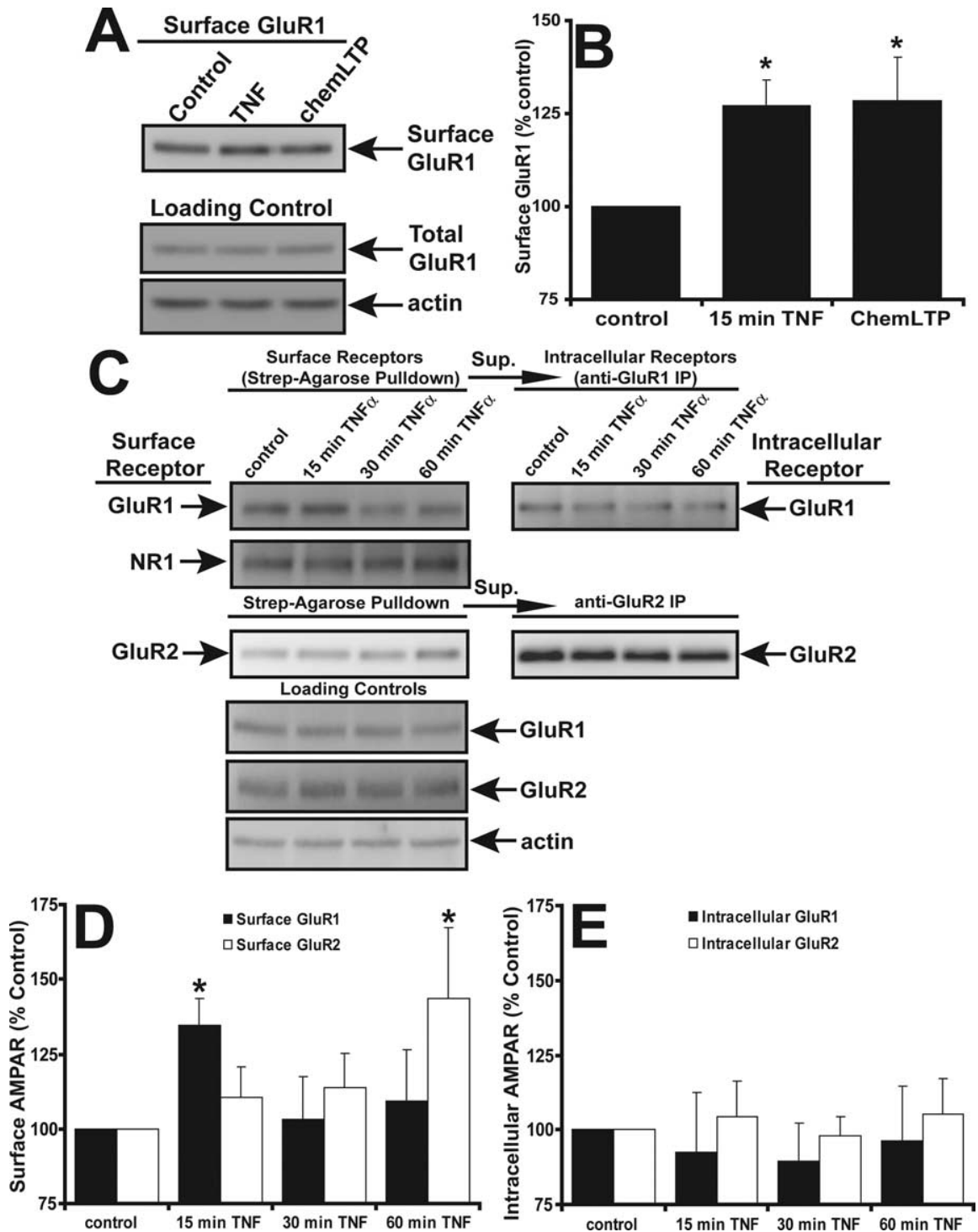

Figure 2. TNF $\alpha$ induces a rapid delivery of endogenous GluR1 and a more delayed delivery of GluR2 to the plasma membrane as shown by biochemical analysis. $\boldsymbol{A}$, Control, untreated neurons or neurons treated with TNF $\alpha$ for 15 min or glycine [long-term potentiation chemical induction protocol (chemLTP); another method for inducing surface AMPAR delivery] and surface biotinylated. A total of $100 \mu \mathrm{g}$ of soluble protein was processed for streptavidin-agarose pulldowns (see Materials and Methods). A total of $5 \mu \mathrm{g}$ of total lysate from each condition was immunoblotted for total GluR1 and actin as loading controls (Loading Control). $\boldsymbol{B}$, Immunoblots in $\boldsymbol{A}$ were quantified by densitometry and normalized to lysate controls, and the compiled data were graphed. ${ }^{*} p<$ $0.01 ; n=7$. C, Control neurons or neurons were treated with TNF $\alpha$ for 15, 30, or 60 min and biotinylated as above. Streptavidinagarose was used to precipitate and purify surface biotinylated proteins (left panels, surface receptor); supernatant from these precipitates was immunoprecipitated with either anti-GluR1 or anti-GluR2 antibodies (right panels, intracellular receptor). Precipitates were separated by SDS-PAGE, transferred to PVDF membranes, and immunoblotted with the antibodies to the proteins indicated. A total of $5 \mu \mathrm{g}$ of lysate (bottom panel) from each condition was immunoblotted as loading controls. D, Immunoblots of surface receptors in $C$ were quantified by densitometry and normalized to actin lysate controls, and the compiled data were graphed. $\boldsymbol{E}$, Immunoblots of intracellular receptors in $\boldsymbol{C}$ were quantified by densitometry and normalized to actin lysate controls, and the compiled data were graphed. Error bars indicate SEM. ${ }^{*} p<0.05 ; n=4$ for each condition.

$\min , 110 \pm 10 \%$; $30 \mathrm{~min}, 113 \pm 16 \%$; $60 \mathrm{~min}, 143 \pm 23 \%$; $n=4$; $p<0.05,60$ min compared with control) (Fig. 2C,E). Intracellular levels of GluR1 or GluR2 did not significantly change (GluR1: $15 \mathrm{~min}, 92 \pm 20 \%$; $30 \mathrm{~min}, 89 \pm 12 \%$; $60 \mathrm{~min}, 96 \pm 18 \% ; n=4$; GluR2: $15 \mathrm{~min}, 104 \pm 12 \%$; $30 \mathrm{~min}, 97 \pm 6 \%$; $60 \mathrm{~min}, 105 \pm$ $11 \% ; n=4)$; however, we do observe a trend toward less intracellular GluR1 at $15 \mathrm{~min}$ of $\mathrm{TNF} \alpha$ treatment, which correlates with the increase in surface GluR1.

The pattern and trend of the data from the microscopy and the biochemistry were similar; however, the biochemical analysis proved less sensitive than the immunofluorescence, possibly because the biochemical analysis measures surface and internal proteins from all cell types in our mixed hippocampal cultures. To eliminate the possibility that astrocytes contributed significantly to this biochemical detection of surface or internal GluR1 or GluR2, we performed the surface biotinylation analysis on pure astrocyte cultures. We detected no surface AMPARs and barely detectable intracellular GluR2 (data not shown). As a control for the specificity of the effect of TNF $\alpha$ on surface AMPARs, we assayed the NR1 subunit of the NMDA receptor (Fig. 2C). Surface NR1 levels did not change significantly $(n=4)$ (data not shown) in agreement with previous data (Beattie et al., 2002).

These data correlate with our immunofluorescence observations that surface GluR1 levels increase within $15 \mathrm{~min}$ of TNF $\alpha$ exposure and then gradually decrease to baseline by $1 \mathrm{~h}$. During this same time frame, surface GluR2 levels have a different temporal profile. Surface GluR2 does not significantly increase until 60 min after TNF $\alpha$ exposure. This suggests that $\mathrm{TNF} \alpha$ initially induces a rapid increase in surface GluR2-lacking CPAMPARs and then causes a slower increase in GluR2-containing (possibly GluR2-3) surface AMPARs. This sequence of initial CP-AMPARs surface delivery followed by replacement with GluR2-containing AMPARs is reminiscent of the trafficking seen during longterm potentiation (LTP) at CA1 hippocampal synapses (Plant et al., 2006). This overall net increase in surface AMPARs seen after TNF $\alpha$ exposure could increase neuronal excitability and sensitivity to excitotoxic cell death.

\section{The TNF $\alpha$-induced surface AMPAR increase is attributable to plasma membrane insertion of intracellularly derived receptors visualized by live confocal microscopy}

The experiments above using fluorescence microscopy of fixed neurons allow us to quantitatively measure relative detectable AMPAR surface localization between groups of cultured hippocampal neurons at discrete time points after TNF $\alpha$ treatment. This technique can also be used to selectively or comparatively measure the surface expression of GluR1and GluR2-containing AMPARs in relationship to synaptic markers (see Figs. 4, 5). Our present data using this technique along with data from our previous studies suggest that these newly detected receptors are intracellularly derived (Beattie et al., 2002; Stellwagen et al., 2005). However, because the fixed-tissue data has time and spatial resolution limitations, we cannot use them to eliminate the possibility that the newly detectable recep- 
tors are the result of aggregation of diffuse surface-localized AMPARs already present on the plasma membrane. Additionally, this technique does not allow us to observe AMPAR localization changes in a single cell after TNF $\alpha$ treatment. To specifically detect any trafficking of intracellularly derived GluR1 to the plasma membrane of individual hippocampal neurons before, during, and after TNF $\alpha$ application, we took advantage of the properties of the SEP form of green fluorescent protein. This is an engineered form of green fluorescent protein whose fluorescence under blue light $(488 \mathrm{~nm})$ illumination is quenched at intravesicular $\mathrm{pH}$ values of $<6$ (Miesenbock et al., 1998). Fusion of acidic intracellular vesicles containing SEP with the plasma membrane exposes this marker to the higher $\mathrm{pH}$ of the extracellular environment ( $\mathrm{pH} \sim 7.4$ ) and results in an instantaneous rise in fluorescence of SEP. Therefore, SEP serves as a useful tool to visualize the delivery of new receptor-SEP fusion proteins to the cell surface from intracellular pools (Ashby et al., 2004; Kopec et al., 2006; Yudowski et al., 2006).

We fused SEP to the extracellular, N terminus of GluR1 (SEP-GluR1) to observe plasma membrane delivery of intracellular vesicles containing GluR1 in response to TNF $\alpha$ with live time-lapse confocal microscopy (Yudowski et al., 2007). To observe only newly membrane inserted SEP-GluR1 AMPARs, we adopted a bleaching protocol to quench the fluorescence of any SEP-GluR1 already on the neuron surface (see Materials and Methods). We then allowed neurons to recover in the presence or absence of TNF $\alpha$ for $15 \mathrm{~min}$. Figure 3, left panels, shows an SEP-GluR1 transfected neuron before bleaching (Pre-Bleach), immediately after bleaching (PostBleach), and $15 \mathrm{~min}$ of recovery after bleaching (15 min Recov.). In these untreated, control neurons, we observed very little increase in fluorescence intensity. In contrast, after 15 $\min \mathrm{TNF} \alpha$ treatment, we observed a marked increase in surface fluorescence, often in clusters (Fig. 3, bottom right panel). An analysis of the total surface SEP-GluR1 fluorescence after 15 min of bleach recovery with and without TNF $\alpha$ revealed $\sim 50 \%$ increase in TNF $\alpha$-treated neurons (percentage change in surface fluorescence, $148 \pm 9 \%$ ) compared with control untreated neurons (percentage change in surface fluorescence, $94 \pm 12 \%)(n=4$ neurons; $p<0.05)$. These data agree with our immunofluorescence data showing an increase in endogenous surface GluR1 (Fig. 1C). These data indicate that TNF $\alpha$ stimulates the delivery of new GluR1 AMPARs from intracellular stores. Photobleaching could have effects on the immediate health of the neuron and alter normal AMPAR trafficking, but our differential results after photobleaching with control compared with TNF $\alpha$ application supports our contention that the amount of photobleaching we used did not perturb neurons enough to prevent rapid trafficking. Additionally, experiments done without the photobleaching also showed a similar increase of surface SEP-GluR1 over background levels after TNF $\alpha$ treatment (data not shown).
Control
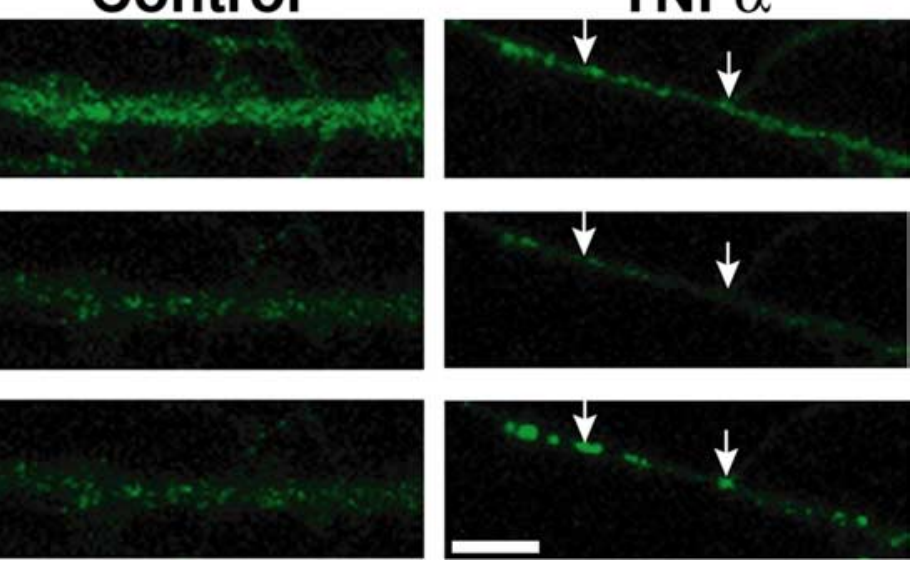

Figure 3. Live confocal imaging of SEP-GluR1-transfected hippocampal neurons treated with TNF $\alpha$ demonstrates exocytosis and rapid surface expression of intracellularly derived SEP-GluR1. The 14 div rat hippocampal neurons AMAXA transfected with (

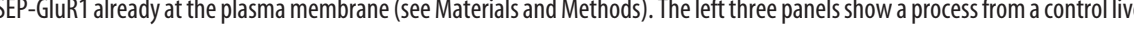
cence, $148 \pm 9 \%$ ) compared with control, untreated neurons (percentage change in surface fluorescence, $94 \pm 12 \% ; n=4$ neurons; $p<0.05)$. Scale bar, $5 \mu \mathrm{m}$.

TNF $\alpha$ increases extrasynaptic surface localization of surface GluR1 in hippocampal neurons

Having established that TNF $\alpha$ induces a maximal surface GluR1 localization at $15 \mathrm{~min}$, we next sought to distinguish AMPARs delivered to synaptic or extrasynaptic regions and measure their distribution at this time point. Extrasynaptic AMPARs are relevant to both synaptic function and excitotoxicity. GluR1containing AMPARs have been demonstrated to be "primed" in at least two different cases. Activation of the $\mathrm{D}_{1}$ dopamine receptor induces a rapid increase in extrasynaptic surface GluR1, and subsequent NMDA receptor stimulation induces an increase in synaptic GluR1 (Sun et al., 2005; Gao et al., 2006). Furthermore, increased serine-845 phosphorylation of GluR1 was shown to correspond with rapid trafficking of GluR1 AMPARs to extrasynaptic plasma membrane before mobilization to synaptic sites during synaptic activity (Oh et al., 2006). In addition, GluR1containing AMPARs contribute to inappropriate excitability leading to excitotoxic death during neuronal injury situations in which neurons are exposed to increases in glutamate concentration (Olney and de Gubareff, 1978; Choi, 1994; Mattson and Chan, 2003).

First, we used immunofluorescent microscopy to measure surface GluR1 localized at synapses with and without TNF $\alpha$ treatment. Hippocampal cultures were treated with TNF $\alpha$ for 15 min, fixed, and stained for surface GluR1 and the well established postsynaptic marker PSD-95 (see Materials and Methods). We performed dual-channel confocal microscopy of dendritic surface GluR1 and total PSD-95 of both control neurons and neurons with $15 \mathrm{~min}$ of TNF $\alpha$ treatment (Fig. 4A). Merging the two, single-plane, $0.5 \mu \mathrm{m}$-thick images revealed overlapping regions of colocalization in yellow (Fig. $4 A$ ). We detected surface GluR1 at both synaptic (overlapping with PSD-95) and extrasynaptic (non-PSD-95-overlapping) sites. Quantitation of overlapping 

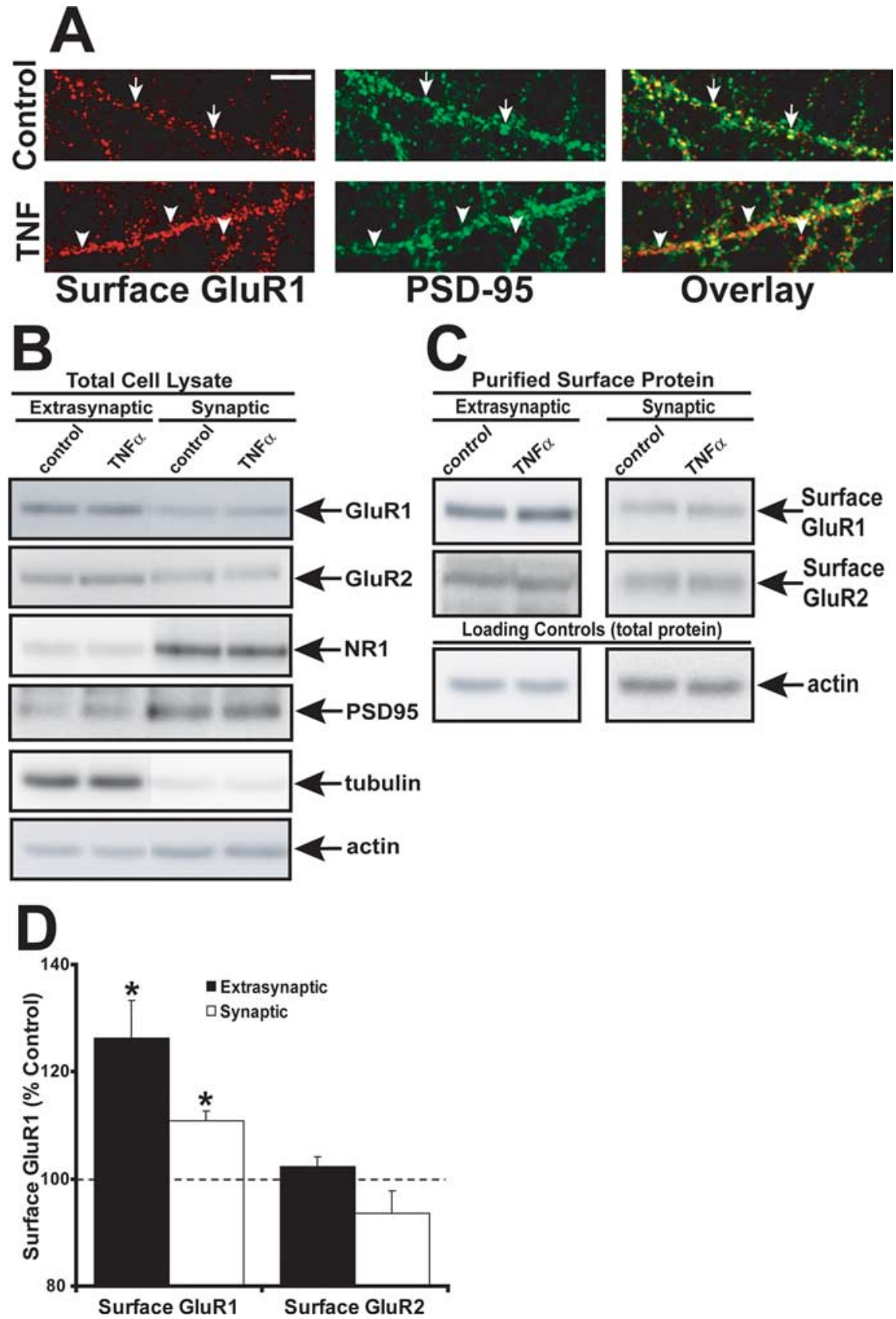

Figure 4. Extrasynaptic surface GluR1 is significantly increased by TNF $\alpha$ treatment. $A$, Hippocampal neurons were costained with the synaptic marker anti-PSD-95 (green) and anti-GluR1 (red) and imaged by indirect immunofluorescence confocal microscopy. The image at the right displays overlaid images with overlapping fluorescence in yellow. The arrows in the top panels indicate colocalization of GluR1 with PSD-95. The arrowheads in the bottom panels indicate GluR1 not colocalizing with PSD-95. Compiled image quantitation from three experiments demonstrates an increase of $19 \pm 7 \%$ compared with control ( $p<0.001 ; n=16)$. Scale bar, $5 \mu \mathrm{m}$. $\boldsymbol{B}$, To biochemically isolate surface AMPARs, hippocampal cultures were treated with TNF $\alpha$ for $15 \mathrm{~min}$ or not treated (control), surface proteins were biotinylated, and neurons were subjected to biochemical synaptic fractionation based on detergent solubility (see Materials and Methods). Total cell lysates from these fractionations $(5 \mu \mathrm{g})$ were immunoblotted for the synaptic marker NR1 (NMDA receptor subunit) and PSD95, which were enriched in the synaptic fraction, whereas GluR1 is mostly extrasynaptic. C, Surface biotinylated proteins from both extrasynaptic and synaptic fractions were purified by streptavidin-agarose and immunoblotted with anti-GluR1 and anti-GluR2 antibodies. $\boldsymbol{D}$, Graph of actin-normalized compiled data from immunoblots of TNF $\alpha$-treated neurons performed as in C. Surface GluR1 is significantly enriched at both extrasynaptic (black bars; ${ }^{*} p<0.001 ; n=8$ ) fractions and synaptic fractions (white bars; ${ }^{*} p<0.001 ; n=5$ ), whereas GluR2 levels do not change. Error bars indicate SEM.

dendritic surface GluR1 with PSD-95 revealed a significant increase in the amount of GluR1 not colocalized with PSD-95 (extrasynaptic) in the TNF $\alpha$-treated samples (increase of $19 \pm 7 \%$ compared with control; $p<0.001 ; n=16-19$ neurons, 3 experiments). Because the overall surface localization of GluR1 goes up with $\mathrm{TNF} \alpha$, this increase implies a substantial increase in extrasynaptic GluR1 surface localization.

To confirm these quantitative microscopic results, we used a technique to biochemically enrich surface biotinylated cell lysate fractions for either synaptic or extrasynaptic protein. Hippocampal cultures were either left untreated or treated with $\mathrm{TNF} \alpha$ for $15 \mathrm{~min}$, and the surface proteins were biotinylated and cell lysates were processed for biochemical synaptic or extrasynaptic enrichment based on differential detergent solubility (Jo et al., 1999; Chen et al., 2000; Oh et al., 2006) (see Materials and Methods). In total cell lysates from these fractionations, proteins from the $1 \%$ NP-40 soluble fraction ("extrasynaptic") or 1\% NP-40 insoluble fraction ("synaptic") were resolved by SDS-PAGE, transferred to PVDF membrane, and immunoblotted for GluR1, GluR2, and the postsynaptic markers NR1 (NMDA receptor subunit) and PSD-95. NR1 and PSD-95 were greatly enriched in the synaptic fraction of the total cell lysates agreeing with previous measurements of these markers (Jo et al., 1999; Chen et al., 2000), and GluR1 was found to be mostly extrasynaptic (Fig. 4B). In the TNF $\alpha$-treated samples, quantitation of GluR1 in the surface, extrasynaptic, and synaptic fractions revealed significant enrichment compared with control samples (Fig. 4C,D) (extrasynaptic, $126 \pm 7 \%, n=8$; synaptic, $110 \pm$ $2 \%, n=5 ; p<0.001$ compared with control). Surface extrasynaptic or synaptic GluR2 levels did not change significantly with TNF $\alpha$ treatment (Fig. 4C,D) (extrasynaptic, $102 \pm 2 \%, n=8$; synaptic, $93.5 \pm 4 \%, n=5$ ). Together with our microscopic synaptic colocalization, these data indicate that a significant portion of TNF $\alpha$-induced surface accumulation of GluR1 AMPARs is extrasynaptic.

TNF $\alpha$ reduces colocalization of surface GluR1 with GluR2 in hippocampal neurons and increases the surface delivery of extrasynaptic GluR2-lacking AMPARs

The GluR2 AMPAR subunit contains an edited arginine amino acid that lines the ion channel of heteromeric GluR1/2 and GluR2/3 AMPARs that blocks passage of $\mathrm{Ca}^{2+}$ into cells during neuronal depolarization (Hollmann et al., 1991; Burnashev et al., 1992). Without this property of the GluR2 subunit, homomeric GluR1 AMPARs are permeable to $\mathrm{Ca}^{2+}$. Indeed, these GluR2-lacking AMPARs are found on hippocampal neurons (Kumar et al., 2002; Ogoshi and Weiss, 2003; Ju et al., 2004; Thiagarajan et al., 2005) and participate in the normal functioning of neurons by contributing to synaptic strengthening (Gu et al., 1996; Plant et 
al., 2006). Our previous immunofluorescence and biochemical data demonstrated that $\mathrm{TNF} \alpha$ significantly increased surface levels of GluR1, but not GluR2 (Stellwagen et al., 2005). Electrophysiological detection of the increase in miniature EPSC (mEPSC) caused by TNF $\alpha$ was also blocked by an inhibitor specific to GluR1-homomeric AMPARs [N-(4-hydroxyphenylpropanoyl) (HPP)-spermine] (Stellwagen et al., 2005). Importantly, another study demonstrated the TNF $\alpha$-induced surface increase of $\mathrm{Ca}^{2+}$ permeable AMPARs by examining $\mathrm{Ca}^{2+}$ and $\mathrm{Co}^{2+}$ uptake in hippocampal slices (Ogoshi et al., 2005). These data, along with our results above describing increased levels of extrasynaptic GluR1, suggest that TNF $\alpha$ increases the rapid delivery of extrasynaptic surface GluR2lacking/homomeric GluR1 AMPARs from intracellular locations.

To confirm these findings, we first asked whether surface GluR2-lacking receptors increased compared with GluR2-containing receptors after TNF $\alpha$ treatment. To test this, we used confocal microscopy to detect colocalization of surface GluR1 and surface GluR2 in the presence or absence of exogenous TNF $\alpha$. Neurons were treated for 15 min with $\mathrm{TNF} \alpha$ or left untreated and then fixed and stained with extracellular epitopedirected anti-GluR1 and anti-GluR2 antibodies under nonpermeabilizing conditions (Fig. 5A). Quantification of the amount of dendritic GluR1 colocalizing with GluR2 demonstrates a decrease in colocalization of these two proteins (decrease to $72 \pm 5 \%$ compared with control; $p<0.001 ; n=15,3$ experiments). These results support the idea that new surface delivery of GluR2-lacking AMPARs is induced by TNF $\alpha$ (Stellwagen et al., 2005).

To determine the synaptic and extrasynaptic plasma membrane distribution of these surface-delivered GluR2-lacking AMPARs, we used a biochemical approach based on the detergent solubility of the synapse as in Figure 4. Using biotinylated and detergent-fractionated hippocampal extract derived from control or TNF $\alpha$-treated cultures, we first immunoprecipitated GluR2 AMPARs using anti-GluR2 antibodies, which effectively removes GluR2-containing complexes from the extract (data not shown) (Oh and Derkach, 2005). The remaining GluR2-depleted supernatant was then incubated with streptavidin-agarose to precipitate surface biotinylated protein and immunoblotted for GluR1. We did not detect a significant change in surface GluR2lacking GluR1 AMPARs in synaptic extracts of TNF $\alpha$-treated neuron cultures (Fig. $5 B, D)(86 \pm 14 \%$ of control; $n=5)$. However, surface biotinylated extrasynaptic extracts of TNF $\alpha$-treated cultures showed a significant increase in surface GluR2-lacking GluR1 AMPARs (Fig. 5C,D) (129 \pm 9\% of control; $p<0.001$; $n=8)$. These biochemical data indicate that TNF $\alpha$ causes a significant increase in extrasynaptic surface GluR2-lacking AMPARs.

Hippocampal neurons exposed to TNF $\alpha$ show increased vulnerability to excitotoxicity through $\mathrm{Ca}^{2+}$-permeable AMPAR activation

The functional consequences of TNF $\alpha$-induced surface localization of CP-AMPARs to extrasynaptic plasma membrane in neurons may include excess $\mathrm{Ca}^{2+}$ influx and subsequent excitotoxicity (Ogoshi and Weiss, 2003; Ogoshi et al., 2005; Kwak and Weiss, 2006). This is especially relevant in traumatic injury situations in which CNS injury or dysfunction may lead to unregulated glutamate release and spillover to extrasynaptic receptors. Thus, our observations of increased extrasynaptic AMPARs after 


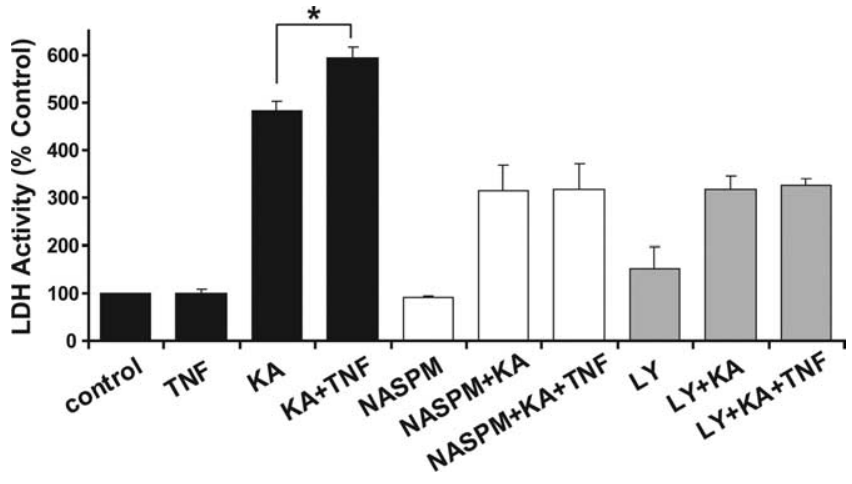

Figure 6. Hippocampal neurons preexposed to TNF $\alpha$ display increased vulnerability to excitotoxicity. Neurons were left untreated (control) or pretreated with TNF $\alpha$ (TNF) alone or in combination with $50 \mu \mathrm{m}$ LY294,002 (LY), $50 \mu \mathrm{m}$ NASPM (NASPM) for $15 \mathrm{~min}$. Kainate at $20 \mu \mathrm{M}$ was then added to untreated (KA), TNF $\alpha$-pretreated (TNF+KA), drug pretreated (LY+KA NASPM + KA), or neurons pretreated with drug and TNF $\alpha(L Y+K A+T N F ; N A S P M+K A+T N F)$ and incubated for $18 \mathrm{~h}$. The graph is the compiled data of lactose dehydrogenase activity released from dead or dying cells into the incubation media normalized to untreated controls (see Materials and Methods). $n=4$ experiments, 4 samples per experiment; ${ }^{*} p<0.05$ compared with kainate alone. Error bars indicate SEM.

exposure to TNF $\alpha$ suggest that this activity may potentiate excitotoxic cell death.

To test this idea, we used an established LDH neuron excitotoxicity assay to measure neuron death in our hippocampal cultures (Patel et al., 1993; Glass et al., 2004). LDH is a stable cytosolic enzyme released during cell lysis from dead or dying cells and can be easily quantitated by using a colorimetric assay to measure the amount of $\mathrm{LDH}$ released into the surrounding medium.

Hippocampal neurons were treated with $\mathrm{TNF} \alpha$ for $15 \mathrm{~min}$ or left untreated (control). Then, the excitotoxic AMPAR agonist kainate $(20 \mu \mathrm{M})$ was added and cultures were incubated for $18 \mathrm{~h}$. Culture supernatant was then assayed for LDH activity. Treating neurons with TNF $\alpha$ for $18 \mathrm{~h}$ produced no significant increase in toxicity $(100 \pm 8 \%)$ from untreated control samples. Exposure to the excitotoxic drug kainate increased the level of toxicity to $481 \pm 21 \%$ compared with controls (Fig. 6, black bars). Pretreating the neurons with TNF $\alpha$ for 15 min followed by kainate treatment led to significantly more neuron death (20\%) than kainate alone (Fig. 6, black bars) ( $594 \pm 22 \%$ from control; significance compared with kainate alone: $p>0.05, n=4)$. Experiments were also performed with lower concentrations of KA. KA at $2 \mu \mathrm{M}$ did not produce an excitotoxic effect after $18 \mathrm{~h}$ of exposure and no excitotoxic increase with the addition of TNF $\alpha ; 10 \mu \mathrm{M}$ KA plus TNF $\alpha$ compared with $10 \mu \mathrm{M}$ KA alone showed only a slight, insignificant increase in excitotoxicity (7\% increase: $10 \mu \mathrm{M} \mathrm{KA}$, $144 \pm 12 \%$; TNF plus $10 \mu \mathrm{M} \mathrm{KA}, 155 \pm 8 \% ; n=3$ ) (data not shown). Neurons pretreated with the AMPAR/KA receptorspecific antagonist CNQX $(10 \mu \mathrm{M})$ before exposure to kainate were completely protected from excitotoxicity (97 $\pm 5 \%$ compared with control) (data not shown), indicating that the cell death produced by kainate requires AMPAR/KA receptor activity. These results are in agreement with previous in vitro hippocampal studies showing the AMPAR dependence of TNF $\alpha$ potentiated neuron death (Bernardino et al., 2005).

To further support the hypothesis that TNF $\alpha$ potentiates kainate excitotoxicity through increasing the number of surface AMPARs, we blocked the PI3K pathway with the inhibitor LY (50 $\mu \mathrm{M})$. LY was shown previously to inhibit the TNF $\alpha$-induced surface AMPAR delivery (Stellwagen et al., 2005), and we tested whether it could reduce or eliminate the TNF $\alpha$ excitotoxic potentiation effect. LY alone had no effect on excitotoxicity during this treatment protocol, showing little difference from controls (Fig. 6, gray bars) $(151 \pm 45 \%$ of control). LY pretreatment reduced the excitotoxic effect of kainate to $315 \pm 29 \%$ of control, a $34.5 \%$ reduction compared with kainate alone (Fig. 6) $(p<$ $0.005)$. When TNF $\alpha$ was added to the pretreatment conditions with LY, no additional potentiation of toxicity was observed (Fig. 6) $(326 \pm 12 \%$; significance compared with LY plus kainate, $p=$ $0.75)$. These data suggest that blocking the PI3 kinase pathway could eliminate TNF $\alpha$-mediated potentiation of kainate excitotoxicity.

The immunofluorescence and biochemical data presented above as well as in previous studies (Ogoshi et al., 2005; Stellwagen et al., 2005) suggest that TNF $\alpha$ increases the surface delivery of $\mathrm{Ca}^{2+}$-permeable, GluR2-lacking AMPARs within $15 \mathrm{~min}$ of TNF $\alpha$ exposure. $\mathrm{Ca}^{2+}$-permeable AMPARs have been demonstrated to be major mediators of excitotoxic cell death (Carriedo et al., 1996; Oguro et al., 1999; Kwak and Weiss, 2006). If these $\mathrm{Ca}^{2+}$-permeable AMPARs are a significant component of the TNF $\alpha$-induced surface AMPAR accumulation, then specifically blocking their activity, and thus $\mathrm{Ca}^{2+}$ influx through these channels, should reduce the extent of kainate-induced toxicity. Neurons were pretreated with the $\mathrm{Ca}^{2+}$-permeable AMPAR antagonist NASPM ( $50 \mu \mathrm{M}$; synthetic joro spider toxin analog) with and without TNF $\alpha$ for 15 min before kainate exposure. NASPM alone had no effect on excitotoxicity during this treatment protocol (Fig. 6) (89 $\pm 4 \%$ of control). Pretreatment with NASPM reduced the amount of kainate-induced excitotoxicity to $313 \pm$ $54 \%$ of control, a 35\% reduction from kainate treatment alone (Fig. 6) $(p<0.05)$. This reduction in toxicity from kainate treatment may reflect the block of existing surface GluR2-lacking AMPARs, and the remaining cell death induced through activation of GluR2-containing AMPARs and kainate receptors. Unlike the potentiation observed with TNF $\alpha$ alone (Fig. 6, black bars), pretreatment of cultures with NASPM followed by KA plus TNF $\alpha$ produced no additional potentiation (Fig. 6, white bars) $(317 \pm 53 \% ; p=0.95)$. These functional data suggest that blocking CP-AMPARs eliminates the TNF $\alpha$-mediated potentiation of kainate excitotoxicity and support the data above indicating that TNF $\alpha$ increases surface GluR2-lacking CP-AMPARs. Together, these results show that TNF $\alpha$-mediated surface delivery of CPAMPARs contributes to the excitotoxic vulnerability of neurons and potentiates neuron injury and death.

\section{Discussion}

We used live-cell microscopy, fixed-cell microscopy, and biochemical analysis to detail the pattern, distribution, and subunit composition of TNF $\alpha$-induced AMPAR surface expression. Our experiments measuring the potentiation of kainate-induced excitotoxicity by TNF $\alpha$ show the specific relevance of CP-AMPARs to neuronal death. This work adds new detail to our previous studies supporting the rapid (after 15 min of TNF $\alpha$ exposure) surface delivery of GluR2-lacking CP-AMPARs through a PI3 kinase-dependent mechanism (Beattie et al., 2002; Stellwagen et al., 2005).

Our live imaging data of TNF $\alpha$-induced surface delivery of SEP-GluR1 in hippocampal neurons confirms that the source of the increased AMPAR surface accumulation seen in our original observations is intracellular and is not simply the aggregation of receptors already at the plasma membrane. Future studies will examine the nature of these AMPAR intracellular source com- 
partments, yet it is likely that at least some of these will include recycling endosomes because induction of LTP increases surface AMPARs from these compartments (Park et al., 2004, 2006). Another possibility is the rapid synthesis and translocation of GluR1-containing AMPARs from dendritic shaft-localized endoplasmic reticulum (Job and Eberwine, 2001; Steward and Schuman, 2001; Ju et al., 2004).

Our biochemical and microscopic data examining total surface AMPAR levels over a $1 \mathrm{~h}$ time course of specific TNF $\alpha$ receptor activation is supportive of a maximum increase in total surface accumulation of CP-AMPARs at $15 \mathrm{~min}$, which returns to baseline by $1 \mathrm{~h}$. The amount of increased total surface CPAMPARs ( $~ 50 \%$ above control levels) after 15 min of TNF $\alpha$ is in close agreement with both our previous results (Beattie et al., 2002; Stellwagen et al., 2005) and other studies examining the TNF $\alpha$ effect on AMPARs in hippocampal neuron cultures (Ogoshi et al., 2005). Interestingly, rapid surface delivery of CPAMPARs has also been observed after LTP induction of CA1 hippocampal neurons in slices with maximum surface increases and a time course profile comparable with our present results (Plant et al., 2006). CP-AMPARs are important functionally because they have stronger current passing capabilities compared with GluR2-containing AMPARs and are $\mathrm{Ca}^{2+}$-permeable (Hollmann et al., 1991; Burnashev et al., 1992). When neurons are exposed to excess glutamate after neuronal damage, excessive surface expression of CP-AMPARs induced by increased TNF $\alpha$ levels may lead to the abnormal influx of $\mathrm{Ca}^{2+}$ and overactivation of AMPARs resulting in potentiated excitotoxicity (Gelbard et al., 1993; Chao and $\mathrm{Hu}, 1994$; Hermann et al., 2001; Bernardino et al., 2005).

Our LDH excitotoxicity data agree with studies showing an increase in GluR1 levels in NT2 cells after TNF $\alpha$ treatment and potentiation of kainate-induced cell death (Yu et al., 2002). Importantly, our current data show that specifically blocking the activity of CP-AMPARs with NASPM eliminates the potentiation of excitotoxicity by $\mathrm{TNF} \alpha$. Additionally, our functional kainateinduced excitotoxicity assay demonstrated that blocking TNF $\alpha$ induced surface delivery AMPARs with the PI3 kinase inhibitor LY294,002 also eliminates potentiation of excitotoxic neuron death. The application of TNF $\alpha$ in our in vitro assay for $18 \mathrm{~h}$ did not itself increase neuron death, suggesting that programmed apoptotic death did not contribute to the kainate plus TNF $\alpha$ potentiation of neuron death. These results are in agreement with previous in vitro hippocampal slice studies showing that AMPAinduced excitotoxicity was dependent on the TNF $\alpha$ receptor TNFR1 but not the TNF $\alpha$ receptor TNFR2 (Bernardino et al., 2005). These results in combination with our data demonstrating TNF $\alpha$-induced trafficking through TNFR1 activation (Stellwagen et al., 2005) fit the hypothesis that TNFR1 activation may contribute to excitotoxic death, whereas TNFR2 may signal for neuroprotection (Fontaine et al., 2002).

Increases in total surface levels of GluR2-containing AMPARs as seen by our biochemical analysis follow a more delayed time course than GluR2-lacking CP-AMPARs with a significant increase after $1 \mathrm{~h}$ of TNF $\alpha$ exposure. These results agree with other findings that GluR1-containing AMPARs are rapidly trafficked to synapses after LTP induction and then are gradually replaced by GluR2-containing AMPARs after LTP induction (Hayashi et al., 2000; Shi et al., 2001). This suggests that CP-AMPARs and GluR2-containing AMPARs are recruited to or maintained on the surface by different mechanisms. Much of the research into differential trafficking of GluR1 and GluR2 has focused on protein-protein interactions in the PSD (Malinow and Malenka,
2002; Bredt and Nicoll, 2003), yet our biochemical data show that most of the increase in surface GluR2-lacking AMPARs elicited by TNF $\alpha$ is extrasynaptic. How TNF $\alpha$ induces differential surface AMPAR subunit composition is unclear, but we established that glial-derived $\mathrm{TNF} \alpha$ acts specifically through the high-affinity TNFR1 subtype of TNF receptor to increase surface AMPARs; inhibiting the PI3 kinase pathway to block TNF $\alpha$-induced surface trafficking of AMPARs (Stellwagen et al., 2005). Future studies will be aimed at further identifying components of this signaling cascade in the hopes that specifically inhibiting key steps may prevent the damaging effects of excessive surface CP-AMPARs.

Our cell surface biotinylation of GluR1-containing AMPARs (which include GluR1/1 and GluR1/2) detected significant increases in both synaptic and extrasynaptic sites (Fig. 4D). However, the cell surface biotinylation and purification of GluR2lacking/GluR1-containing CP-AMPARs (which likely are GluR1 homomeric) showed a significant increase in extrasynaptic but not synaptic localization (Fig. 5C). A previous electrophysiological experiment has demonstrated that CP-AMPARs can be increased by TNF $\alpha$ at synapses by measuring mEPSCs while blocking CP-AMPARs with the antagonist HPP-spermine (in addition to synaptic activity blockade) (Stellwagen et al., 2005). This block was somewhat small ( $82 \%$ of control) and was measured in single pyramidal neurons. It is possible that our biochemical assay, which pools data from hippocampal pyramidal neurons and interneurons, is unable to detect the small changes measurable by whole-cell electrophysiology of individual pyramidal neurons.

The postinjury milieu in the CNS is a complex mix of activitydriven responses and inflammatory mediators like the inflammatory cytokine TNF $\alpha$. Our intent in this study as in our previous work was to isolate the effect of TNF $\alpha$ on the trafficking of AMPARs in an in vitro model by the addition of inhibitors including TTX and APV (Beattie et al., 2002; Stellwagen et al., 2005). The data presented in this study suggests that specific TNF $\alpha$ receptor activation increases delivery of GluR2-lacking CP-AMPARs to extrasynaptic plasma membrane. The location of initial AMPAR surface delivery is being debated in the literature. Our current results add to the mounting evidence that AMPARs are first exocytosed to extrasynaptic locations. Our recent publication showing that AMPARs are exclusively exocytosed to extrasynaptic plasma membrane after NMDAR activation via chemLTP treatment also supports this hypothesis (Yudowski et al., 2007). Some of the first researchers to support this idea have shown that $D_{1}$ receptor activation increases the extrasynaptic surface pool of AMPAR (step 1) and concurrent NMDAR activity allows for synaptic localization (step 2) (Sun et al., 2005; Gao et al., 2006). Another group also supports this two-step delivery of AMPARs first to extrasynaptic and then to synaptic plasma membrane after LTP induction (Oh et al., 2006). Studies have also demonstrated the surface membrane delivery of AMPARs to extrasynaptic sites during development (King et al., 2006). Other studies show that surface AMPARs can move laterally across the membrane to synapses where they are trapped and stabilized by synaptic activity (Groc et al., 2004; Adesnik et al., 2005; Bats et al., 2007; Ehlers et al., 2007). We believe the TTX and APV activity block we use to isolate TNF $\alpha$-specific components of AMPAR mobilization provides the analytical benefit of capturing AMPARs in extrasynaptic plasma membrane immediately after exocytosis. Future studies in our laboratory will examine the concurrent effects of activity and TNF $\alpha$ signaling on synaptic localization of AMPARs. 
We provide detailed data about trafficking of AMPARs through $1 \mathrm{~h}$ of TNF application. At the end of this hour, we show that the levels of surface GluR2-lacking CP-AMPARs are back to baseline, whereas calcium-impermeant GluR2-containing AMPARs may be moderately increased. This trafficking data in combination with our observation that the specific CP-AMPAR blocker NASPM blocks the potentiation of KA-induced death by TNF $\alpha$ suggests that the potentiation is effected through the initial, rapid increase in GluR2-lacking CP-AMPARs within 15 min of TNF $\alpha$ exposure. These data reveal a previously unexamined window of excitotoxic vulnerability caused by TNF $\alpha$. Inhibiting this activity through modulation of CP-AMPAR trafficking may reduce excitotoxicity after acute trauma or during neurological disorders.

\section{References}

Adesnik H, Nicoll RA, England PM (2005) Photoinactivation of native AMPA receptors reveals their real-time trafficking. Neuron 48:977-985.

Allan SM, Rothwell NJ (2001) Cytokines and acute neurodegeneration. Nat Rev Neurosci 2:734-744.

Ashby MC, De La Rue SA, Ralph GS, Uney J, Collingridge GL, Henley JM (2004) Removal of AMPA receptors (AMPARs) from synapses is preceded by transient endocytosis of extrasynaptic AMPARs. J Neurosci 24:5172-5176.

Banker G, Goslin K (1998) Culturing nerve cells, Ed 2. Cambridge, MA: MIT.

Bats C, Groc L, Choquet D (2007) The interaction between Stargazin and PSD-95 regulates AMPA receptor surface trafficking. Neuron 53:719-734.

Beattie EC, Stellwagen D, Morishita W, Bresnahan JC, Ha BK, Von Zastrow M, Beattie MS, Malenka RC (2002) Control of synaptic strength by glial TNFalpha. Science 295:2282-2285.

Bernardino L, Xapelli S, Silva AP, Jakobsen B, Poulsen FR, Oliveira CR, Vezzani A, Malva JO, Zimmer J (2005) Modulator effects of interleukin-1 $\beta$ and tumor necrosis factor- $\alpha$ on AMPA-induced excitotoxicity in mouse organotypic hippocampal slice cultures. J Neurosci 25:6734-6744.

Boulter J, Hollmann M, O'Shea-Greenfield A, Hartley M, Deneris E, Maron C, Heinemann S (1990) Molecular cloning and functional expression of glutamate receptor subunit genes. Science 249:1033-1037.

Bredt DS, Nicoll RA (2003) AMPA receptor trafficking at excitatory synapses. Neuron 40:361-379.

Burnashev N, Monyer H, Seeburg PH, Sakmann B (1992) Divalent ion permeability of AMPA receptor channels is dominated by the edited form of a single subunit. Neuron 8:189-198.

Carriedo S, Yin H, Weiss J (1996) Motor neurons are selectively vulnerable to AMPA/kainate receptor-mediated injury in vitro. J Neurosci 16:4069-4079.

Carroll RC, Beattie EC, von Zastrow M, Malenka RC (2001) Role of AMPA receptor endocytosis in synaptic plasticity. Nat Rev Neurosci 2:315-324.

Chao CC, Hu S (1994) Tumor necrosis factor-alpha potentiates glutamate neurotoxicity in human fetal brain cell cultures. Dev Neurosci 16:172-179.

Chen L, Chetkovich DM, Petralia RS, Sweeney NT, Kawasaki Y, Wenthold RJ, Bredt DS, Nicoll RA (2000) Stargazin regulates synaptic targeting of AMPA receptors by two distinct mechanisms. Nature 408:936-943.

Choi DW (1994) Glutamate receptors and the induction of excitotoxic neuronal death. Prog Brain Res 100:47-51.

Corona JC, Tapia R (2007) $\mathrm{Ca}^{2+}$-permeable AMPA receptors and intracellular $\mathrm{Ca}^{2+}$ determine motoneuron vulnerability in rat spinal cord in vivo. Neuropharmacology 52:1219-1228.

Ehlers MD, Heine M, Groc L, Lee MC, Choquet D (2007) Diffusional trapping of GluR1 AMPA receptors by input-specific synaptic activity. Neuron 54:447-460.

Fergusen AR, Christensen RN, Gensel JC, Miller BA, Beattie EC, Bresnahan JC, Beattie MS (2006) Effect of tumor necrosis factor alpha on AMPAtype glutamate receptor trafficking in spinal cord neurons in vivo. Soc Neurosci Abstr 32:475.11.

Fontaine V, Mohand-Said S, Hanoteau N, Fuchs C, Pfizenmaier K, Eisel U (2002) Neurodegenerative and neuroprotective effects of tumor necrosis factor (TNF) in retinal ischemia: opposite roles of TNF receptor 1 and TNF receptor 2. J Neurosci 22:RC216(1-7).

Gao C, Sun X, Wolf ME (2006) Activation of D1 dopamine receptors increases surface expression of AMPA receptors and facilitates their synaptic incorporation in cultured hippocampal neurons. J Neurochem 98:1664-1677.

Gelbard HA, Dzenko KA, DiLoreto D, del Cerro C, del Cerro M, Epstein LG (1993) Neurotoxic effects of tumor necrosis factor alpha in primary human neuronal cultures are mediated by activation of the glutamate AMPA receptor subtype: implications for AIDS neuropathogenesis. Dev Neurosci 15:417-422.

Glass TF, Reeves B, Sharp FR (2004) The impact of excitotoxic blockade on the evolution of injury following combined mechanical and hypoxic insults in primary rat neuronal culture. Neurobiol Dis 17:378-384.

Groc L, Heine M, Cognet L, Brickley K, Stephenson FA, Lounis B, Choquet D (2004) Differential activity-dependent regulation of the lateral mobilities of AMPA and NMDA receptors. Nat Neurosci 7:695-696.

Gu JG, Albuquerque C, Lee CJ, MacDermott AB (1996) Synaptic strengthening through activation of $\mathrm{Ca}^{2+}$-permeable AMPA receptors. Nature 381:793-796.

Hayashi Y, Shi SH, Esteban JA, Piccini A, Poncer JC, Malinow R (2000) Driving AMPA receptors into synapses by LTP and CaMKII: requirement for GluR1 and PDZ domain interaction. Science 287:2262-2267.

Hermann GE, Rogers RC, Bresnahan JC, Beattie MS (2001) Tumor necrosis factor-alpha induces cFOS and strongly potentiates glutamate-mediated cell death in the rat spinal cord. Neurobiol Dis 8:590-599.

Hollmann M, Hartley M, Heinemann S (1991) $\mathrm{Ca}^{2+}$ permeability of KAAMPA-gated glutamate receptor channels depends on subunit composition. Science 252:851-853.

Jo K, Derin R, Li M, Bredt DS (1999) Characterization of MALS/Velis-1, -2, and -3: a family of mammalian LIN-7 homologs enriched at brain synapses in association with the postsynaptic density-95/NMDA receptor postsynaptic complex. J Neurosci 19:4189-4199.

Job C, Eberwine J (2001) Localization and translation of mRNA in dendrites and axons. Nat Rev Neurosci 2:889-898.

Ju W, Morishita W, Tsui J, Gaietta G, Deerinck TJ, Adams SR, Garner CC, Tsien RY, Ellisman MH, Malenka RC (2004) Activity-dependent regulation of dendritic synthesis and trafficking of AMPA receptors. Nat Neurosci 7:244-253.

King AE, Chung RS, Vickers JC, Dickson TC (2006) Localization of glutamate receptors in developing cortical neurons in culture and relationship to susceptibility to excitotoxicity. J Comp Neurol 498:277-294.

Kopec CD, Li B, Wei W, Boehm J, Malinow R (2006) Glutamate receptor exocytosis and spine enlargement during chemically induced long-term potentiation. J Neurosci 26:2000-2009.

Kumar SS, Bacci A, Kharazia V, Huguenard JR (2002) A developmental switch of AMPA receptor subunits in neocortical pyramidal neurons. J Neurosci 22:3005-3015.

Kwak S, Weiss JH (2006) Calcium-permeable AMPA channels in neurodegenerative disease and ischemia. Curr Opin Neurobiol 16:281-287.

Leonoudakis D, Braithwaite SP, Beattie MS, Beattie EC (2004) TNFalphainduced AMPA-receptor trafficking in CNS neurons; relevance to excitotoxicity? Neuron Glia Biol 1:263-273.

Lu W, Man H, Ju W, Trimble WS, MacDonald JF, Wang YT (2001) Activation of synaptic NMDA receptors induces membrane insertion of new AMPA receptors and LTP in cultured hippocampal neurons. Neuron 29:243-254.

Malinow R, Malenka RC (2002) AMPA receptor trafficking and synaptic plasticity. Annu Rev Neurosci 25:103-126.

Mattson MP, Chan SL (2003) Neuronal and glial calcium signaling in Alzheimer's disease. Cell Calcium 34:385-397.

Miesenbock G, De Angelis DA, Rothman JE (1998) Visualizing secretion and synaptic transmission with $\mathrm{pH}$-sensitive green fluorescent proteins. Nature 394:192-195.

Nemeth ZH, Hasko G, Szabo C, Vizi ES (1997) Amrinone and theophylline differentially regulate cytokine and nitric oxide production in endotoxemic mice. Shock 7:371-375.

Noh KM, Yokota H, Mashiko T, Castillo PE, Zukin RS, Bennett MV (2005) Blockade of calcium-permeable AMPA receptors protects hippocampal neurons against global ischemia-induced death. Proc Natl Acad Sci USA 102:12230-12235.

Ogoshi F, Weiss JH (2003) Heterogeneity of $\mathrm{Ca}^{2+}$-permeable AMPA/kai- 
nate channel expression in hippocampal pyramidal neurons: fluorescence imaging and immunocytochemical assessment. J Neurosci 23:10521-10530.

Ogoshi F, Yin HZ, Kuppumbatti Y, Song B, Amindari S, Weiss JH (2005) Tumor necrosis-factor-alpha (TNF-alpha) induces rapid insertion of $\mathrm{Ca}^{2+}$-permeable alpha-amino-3-hydroxyl-5-methyl-4-isoxazolepropionate (AMPA)/kainate (Ca-A/K) channels in a subset of hippocampal pyramidal neurons. Exp Neurol 193:384-393.

Oguro K, Oguro N, Kojima T, Grooms SY, Calderone A, Zheng X, Bennett MV, Zukin RS (1999) Knockdown of AMPA receptor GluR2 expression causes delayed neurodegeneration and increases damage by sublethal ischemia in hippocampal CA1 and CA3 neurons. J Neurosci 19:9218-9227.

Oh MC, Derkach VA (2005) Dominant role of the GluR2 subunit in regulation of AMPA receptors by CaMKII. Nat Neurosci 8:853-854.

Oh MC, Derkach VA, Guire ES, Soderling TR (2006) Extrasynaptic membrane trafficking regulated by GluR1 serine 845 phosphorylation primes AMPA receptors for long-term potentiation. J Biol Chem 281:752-758.

Olney JW, de Gubareff T (1978) Glutamate neurotoxicity and Huntington's chorea. Nature 271:557-559.

Park M, Penick EC, Edwards JG, Kauer JA, Ehlers MD (2004) Recycling endosomes supply AMPA receptors for LTP. Science 305:1972-1975.

Park M, Salgado JM, Ostroff L, Helton TD, Robinson CG, Harris KM, Ehlers MD (2006) Plasticity-induced growth of dendritic spines by exocytic trafficking from recycling endosomes. Neuron 52:817-830.

Patel MN, Yim GK, Isom GE (1993) N-Methyl-D-aspartate receptors mediate cyanide-induced cytotoxicity in hippocampal cultures. Neurotoxicology 14:35-40.

Perry RT, Collins JS, Wiener H, Acton R, Go RC (2001) The role of TNF and its receptors in Alzheimer's disease. Neurobiol Aging 22:873-883.

Pickering M, Cumiskey D, O'Connor JJ (2005) Actions of TNF-alpha on glutamatergic synaptic transmission in the central nervous system. Exp Physiol 90:663-670.

Plant K, Pelkey KA, Bortolotto ZA, Morita D, Terashima A, McBain CJ, Collingridge GL, Isaac JT (2006) Transient incorporation of native GluR2-lacking AMPA receptors during hippocampal long-term potentiation. Nat Neurosci 9:602-604.

Shi S, Hayashi Y, Esteban JA, Malinow R (2001) Subunit-specific rules governing AMPA receptor trafficking to synapses in hippocampal pyramidal neurons. Cell 105:331-343.
Shohami E, Ginis I, Hallenbeck JM (1999) Dual role of tumor necrosis factor alpha in brain injury. Cytokine Growth Factor Rev 10:119-130.

Song I, Huganir RL (2002) Regulation of AMPA receptors during synaptic plasticity. Trends Neurosci 25:578-588.

Stellwagen D, Beattie EC, Seo JY, Malenka RC (2005) Differential regulation of AMPA receptor and GABA receptor trafficking by tumor necrosis factor- $\alpha$. J Neurosci 25:3219-3228.

Steward O, Schuman EM (2001) Protein synthesis at synaptic sites on dendrites. Annu Rev Neurosci 24:299-325.

Sun X, Zhao Y, Wolf ME (2005) Dopamine receptor stimulation modulates AMPA receptor synaptic insertion in prefrontal cortex neurons. J Neurosci 25:7342-7351.

Szelenyi J (2001) Cytokines and the central nervous system. Brain Res Bull 54:329-338.

Thiagarajan TC, Lindskog M, Tsien RW (2005) Adaptation to synaptic inactivity in hippocampal neurons. Neuron 47:725-737.

Tsao PI, von Zastrow M (2000) Type-specific sorting of G protein-coupled receptors after endocytosis. J Biol Chem 275:11130-11140.

Yang L, Lindholm K, Konishi Y, Li R, Shen Y (2002) Target depletion of distinct tumor necrosis factor receptor subtypes reveals hippocampal neuron death and survival through different signal transduction pathways. J Neurosci 22:3025-3032.

Yu Z, Cheng G, Wen X, Wu GD, Lee WT, Pleasure D (2002) Tumor necrosis factor alpha increases neuronal vulnerability to excitotoxic necrosis by inducing expression of the AMPA-glutamate receptor subunit GluR1 via an acid sphingomyelinase- and NF-kappaB-dependent mechanism. Neurobiol Dis 11:199-213.

Yudowski GA, Puthenveedu MA, von Zastrow M (2006) Distinct modes of regulated receptor insertion to the somatodendritic plasma membrane. Nat Neurosci 9:622-627.

Yudowski GA, Puthenveedu MA, Leonoudakis D, Panicker S, Thorn KS, Beattie EC, von Zastrow M (2007) Real-time imaging of discrete exocytic events mediating surface delivery of AMPA receptors. J Neurosci 27:11112-11121.

Zhao X, Bausano B, Pike BR, Newcomb-Fernandez JK, Wang KK, Shohami E, Ringger NC, DeFord SM, Anderson DK, Hayes RL (2001) TNF-alpha stimulates caspase- 3 activation and apoptotic cell death in primary septohippocampal cultures. J Neurosci Res 64:121-131.

Zou JY, Crews FT (2005) TNF alpha potentiates glutamate neurotoxicity by inhibiting glutamate uptake in organotypic brain slice cultures: neuroprotection by NF kappa B inhibition. Brain Res 1034:11-24. 